\title{
Adding linguistic information to parsed corpora
}

SusAn PInTzuK, University of York

\begin{abstract}
No matter how comprehensively corpus builders design their annotation schemes, users frequently find that information is missing that they need for their research. In this methodological paper I describe and illustrate five methods of adding linguistic information to corpora that have been morphosyntactically annotated (=parsed) in the style of Penn treebanks. Some of these methods involve manual operations; some are executed by CorpusSearch functions; some require a combination of manual and automated procedures. Which method is used depends almost entirely on the type of information to be added and the goals of the user. Of course the main goal, regardless of method, is to record within the corpus additional information that can be used for analysis and also retained through further searches and data processing.
\end{abstract}

\section{Introduction}

No matter how comprehensively corpus builders design their annotation schemes, users frequently find that information is missing that they need for their research, and so they must add it on their own. In this methodological paper I discuss and illustrate five methods of adding linguistic information of all types (lexical, phonological, morphological, syntactic, semantic, discourse) to corpora that have been morphosyntactically annotated (=parsed) in the style of Penn treebanks, and the advantages and disadvantages of each method. These five methods are the following: 1) adding information to the ur-text; 2) inserting CODE nodes into the token structure; 3) embedding in- 
formation in coding strings; 4) modifying node labels and structure; and 5) importing token information and other corpus data from the corpus into spreadsheets. Method 1 is necessarily manual, while methods 2 through 5 may involve a combination of manual and automated procedures, functions and tools. Of course the main goal, regardless of method, is to record within the corpus additional information that can be used for analysis and also retained through further searches and data processing. The search engine used for many treebanks, and the one used for the searches and the automated annotation described in this paper, is CorpusSearch (CS). ${ }^{1}$

The manual addition of information may be the simplest procedure but, being manual, it is the most prone to error. Information can be added to the two areas of CS output that are reproduced each time CS is run under default conditions: 1) the token ur-text, which contains the token text and ID without any annotation, and 2) the token structure, including the lexical items. The main difference between the two locations is that material internal to the ur-text is not searchable by CS, while the token structure is the object that is searched and modified by CS queries.

A word of warning is appropriate here: annotation that is added manually cannot be reproduced except by repeating the same manual procedure. Annotation added by CS (i.e. coding strings, structure changes, label changes) can easily be reproduced - unless it is based on annotation that was previously added manually. The availability of automated reproduction is important for three reasons:

1) Files can be lost or damaged. Automated reproduction of annotation is relatively simple; manual reproduction is painful and time-consuming.

2) For most users, whenever we look at the output of a new CS query, we find problems, either in the query or else in the corpus; we then must find and fix the source of the problem and run CS again. One way to facilitate this repetition is to use annotated batch files so that the same processes can be documented and repeated. The use of batch files permits the effortless repetition of what may be a long and complex string of searches. An example of a batch file is given in Appendix.

3) We want other scholars to be able to reproduce our research. With this end in mind, it is encouraging to see that many researchers are making their CS queries available, either in an appendix or

\footnotetext{
${ }^{1}$ The CS software and manual can be downloaded from its sourceforge site: http://corpussearch.sourceforge.net/.
} 
on the web, along with their search results.

In the remainder of this paper, I describe and evaluate the five methods listed above, presenting case studies for each method from my own recent collaborative research. ${ }^{2}$ For readers who are not familiar with CS, some details of the search methodology will be given where space permits; interested readers are referred to the online CS manual. Because of space limitations, the background information and results for each case study are necessarily brief; interested readers are referred to the publications themselves for details and clarifications.

\section{Method 1: Adding information manually to the ur-text.}

The ur-text consists of the words of the token and the token ID without morphosyntactic annotation; CS outputs the ur-text above the structure for each token in the output file. As mentioned above, adding information manually to the ur-text is arguably the simplest procedure, at least in concept, but it has (at least) three major drawbacks: 1) because it is manual, it is prone to error; 2) it must be applied to CS output, not to the original corpus, because the original corpus does not contain ur-text to accompany the token structure; and 3) the ur-text is not searchable by CS, and therefore any added information can be used only by looking directly at the individual tokens in the data file, one by one. ${ }^{3}$ This method was used for some of the tokens in the database for Haeberli et al. 2017, described as Case study 1 below.

Case study 1: Haeberli et al. 2017, investigating verb second (V2) in Old English, looked at fronted pronominal objects to determine whether they can be analyzed as the result of Formal Movement (Frey 2006a,b; Light 2012). CS was used to retrieve all clauses with fronted pronominal objects, but the preceding context was needed to determine the topic type (familiar, aboutness, contrastive, as in Frascarelli and Hinterhölzl 2007). Examples (1) and (2) below show text manually inserted in the ur-text (the text in the area between '/*' and '*/'). In (1) below, the ur-text is enclosed in a box, and the information added manually is in red. The original Old English token, including the token ID, is in black. In (1), the added information is the preceding context and its gloss and the gloss of the token itself.

\footnotetext{
${ }^{2}$ In some cases the procedures documented in the case studies have been simplified for clarification purposes.

${ }^{3}$ Of course CS output, being straight ASCII text, can be read by word-processing software such as Word and TextEdit, so these manual additions can be searched for
} 
(1)

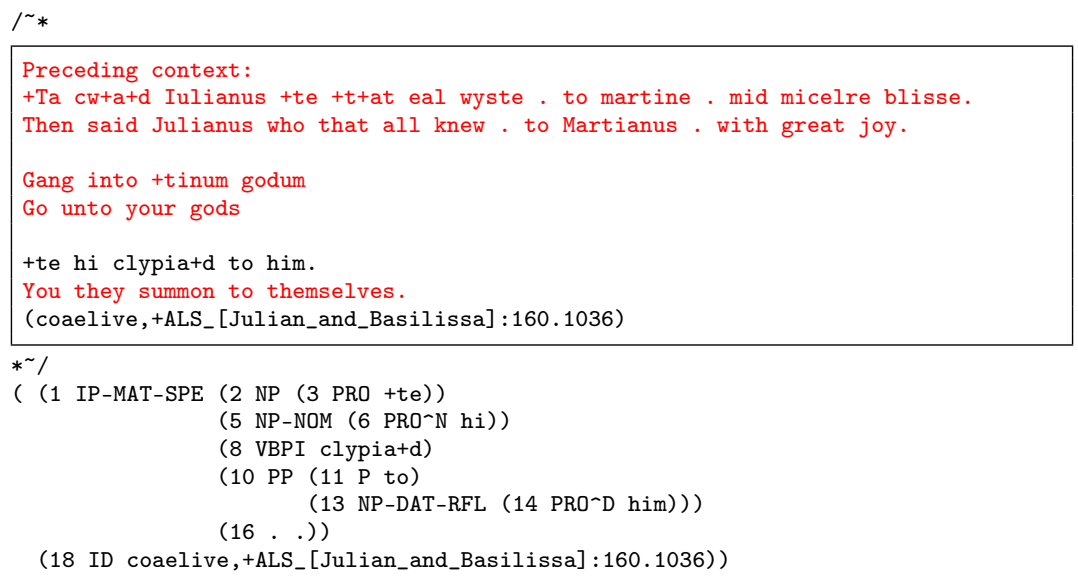

In (2), the added information is the gloss of the token and a comment about structure and word order in the token.

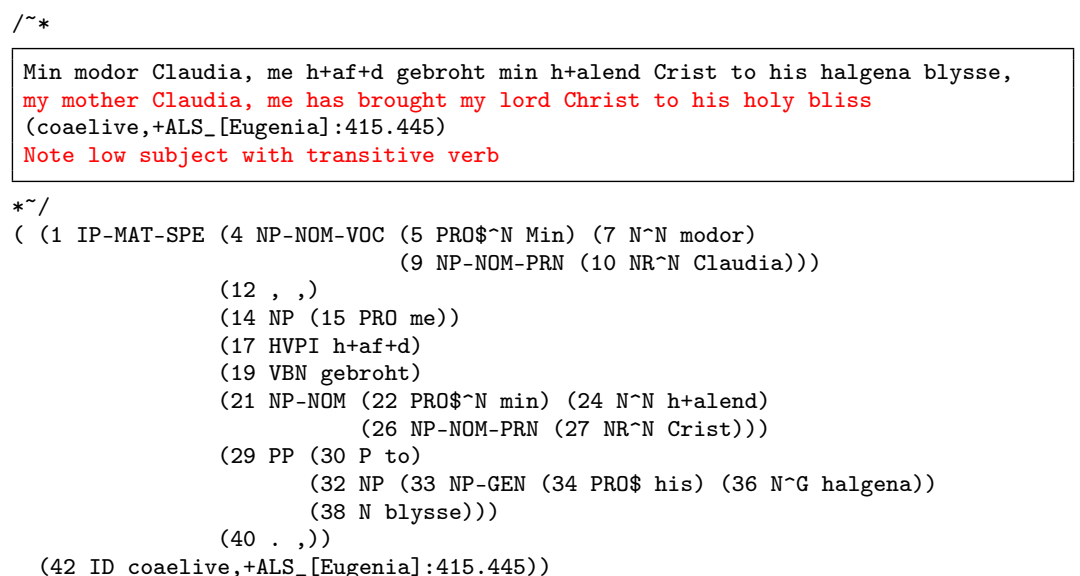

Haeberli et al. 2017 used the preceding context to determine the topic type and then manually added it to the coding string for each token. The counts of the different topic types are shown in Table 1 below; it is clear from these data that non-contrastive object pronouns that serve as familiar topics can be found clause-initially in early English,

in this way. 
contra Light 2012; Haeberli et al. 2017 showed that this pattern could be analysed as in Walkden 2017.

\begin{tabular}{|l|c|c|}
\hline Topic type & $\mathbf{N}$ & $\mathbf{\%}$ \\
\hline contrastive & 18 & $14.4 \%$ \\
\hline aboutness & 42 & $33.6 \%$ \\
\hline familiar & 65 & $52.0 \%$ \\
\hline Total & 125 & $100.0 \%$ \\
\hline
\end{tabular}

TABLE 1: Topic type of fronted pronominal objects in Old English main clauses

\section{Method 2: Inserting CODE nodes into the token structure}

Since inserting nodes is a change in the structure of the token, it can be done at least partially by $\mathrm{CS},{ }^{4}$ and the information added can be accessed by CS in subsequent queries.

Case study 2: Crisma and Pintzuk 2016, building on research developed in Crisma 2015, investigated the development of the indefinite article in Middle English. Table 2 lists the codes and their definitions; Middle English examples are given in Appendix B.

(3) Three-step process for coding and counting NP types

Step 1: Add CODE node with a CS corpus-revision query:

Step 1 Query: This query inserts a CODE node as the first constituent of an NP object

node: $\mathrm{NP}-\mathrm{OB} *$

query: (NP-OB* idomsfirst $\{1\} *$ )

add_leaf_before\{1\}: (CODE <NPTYPE: >)

\footnotetext{
${ }^{4}$ In fact, while the research for this project was carried out, both the CODE nodes and their contents were inserted manually; it would have been less work if CS had been used to insert the nodes and to determine whether or not the relevant NP contained the lexeme an 'one'. In the procedure presented below, the CODE node is inserted by CS, while all other information is inserted manually.
} 


\begin{tabular}{|l|l|}
\hline AN- & an 'one' introduces NP \\
\hline BSG- & bare singular \\
\hline -EXS & existential \\
\hline -GNR & generic \\
\hline -AMB & ambiguous between existential and generic \\
\hline -NPE & $\begin{array}{l}\text { no presupposition of existence (generics and existentials with } \\
\text { narrow scope have this characteristic in common) }\end{array}$ \\
\hline -SDF & $\begin{array}{l}\text { semantically definite (the NP receives a definite interpretation } \\
\text { but is not formally marked as definite) }\end{array}$ \\
\hline -SCOPE-nrw & narrow scope \\
\hline -SCOPE-wd & wide scope \\
\hline -SCOPE-amb & ambiguous scope \\
\hline -SPC & the NP is overtly made specific (e.g. by a relative clause) \\
\hline -NG & the clause contains a negative element \\
\hline
\end{tabular}

TABLE 2: Coding for CODE-NPTYPE node

\section{Step 1 Input:}

( (IP-MAT (NP-SBJ (NPR Eue))

(VBD heold)

(PP (P+NPR iparais))

(NP-OB1 (ADJ long) (N tale))

(PP $(P$ wi $+d)$

(NP (D +te) (N neddre)))

$\left(E_{-} S\right.$.) ) (ID CMANCRIW-1, II.54.519))

\section{Step 1 Output:}

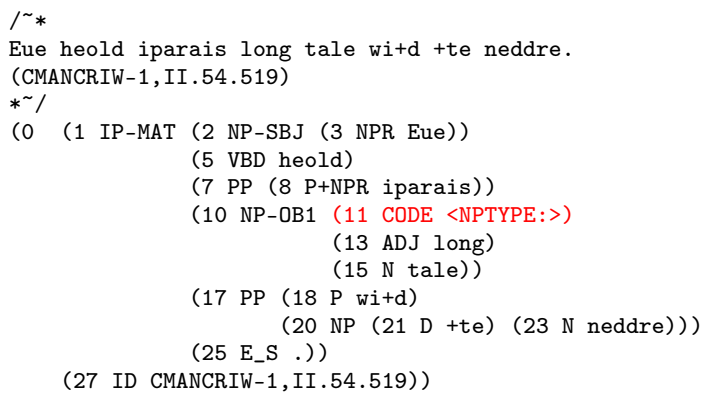

Step 2: Add NP characteristics manually to CODE node

/ *

Eue heold iparais long tale wi+d tte neddre.

Eve held in-paradise (a) long conversation with the serpent

(CMANCRIW-1, II .54.519)

* /

(0 (1 IP-MAT (2 NP-SBJ (3 NPR Eue))

(5 VBD heold)

(7 PP (8 P+NPR iparais))

(10 NP-OB1 (11 CODE <NPTYPE:BSG-EXS>)

(13 ADJ long) 
(15 $\mathrm{N}$ tale))

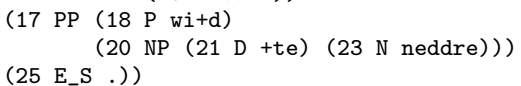

(27 ID CMANCRIW-1, II.54.519))

In Crisma and Pintzuk 2016, all nominal objects were coded in this way. Each type of NP was then 'counted' by searching for each type of CODE node; an example is given in Step 3 Query below. The quantitative results are shown in Table 3 .

Step 3: Count NP types

\section{Step 3 Query:}

node: IP*

query: (NP-OB* idoms CODE)

AND (CODE idoms <NPTYPE: *GNR*>)

\begin{tabular}{|c|c|c|c|c|c|c|c|c|c|c|c|c|c|c|c|c|c|c|c|}
\hline \multirow[b]{2}{*}{$\begin{array}{c}\text { ME } \\
\text { PERIOD }\end{array}$} & \multirow[b]{2}{*}{ TEXT } & \multicolumn{2}{|c|}{ GNR } & \multicolumn{2}{|c|}{ NPE } & \multicolumn{2}{|c|}{$\begin{array}{c}\text { EXS- } \\
\text { SCOPE- } \\
\text { nrw }\end{array}$} & \multicolumn{2}{|c|}{$\begin{array}{c}\text { EXS- } \\
\text { SCOPE- } \\
\text { amb }\end{array}$} & \multicolumn{2}{|c|}{ EXs } & \multicolumn{2}{|c|}{$\mathrm{AMB}$} & \multicolumn{2}{|c|}{$\begin{array}{l}\text { EXS- } \\
\text { SCOPE- } \\
\text { wd }\end{array}$} & \multicolumn{2}{|c|}{ EXS-SPC } & \multicolumn{2}{|c|}{ TOTAL } \\
\hline & & BSG & AN & BSG & AN & BSG & $\mathrm{AN}$ & BSG & AN & BSG & AN & BSG & AN & BSG & AN & BSG & $\mathrm{AN}$ & BSG & AN \\
\hline \multirow[t]{8}{*}{ M1 } & cmpeterb & 0 & 0 & 2 & 1 & 1 & 0 & 0 & 0 & 1 & 2 & 0 & 0 & 0 & 0 & 0 & 6 & 4 & 9 \\
\hline & cmhali & 9 & 2 & 12 & 0 & 1 & 0 & 0 & 0 & 1 & 2 & 0 & 0 & 0 & 0 & 0 & 0 & 23 & 4 \\
\hline & cmjulia & 2 & 0 & 0 & 1 & 1 & 1 & 0 & 0 & 1 & 11 & 0 & 0 & 0 & 0 & 0 & 0 & 4 & 13 \\
\hline & cmkathe & 1 & 0 & 0 & 0 & 1 & 4 & 0 & 0 & 2 & 7 & 0 & 0 & 0 & 1 & 0 & 2 & 4 & 14 \\
\hline & cmmarga & 1 & 0 & 2 & 0 & 3 & 3 & 0 & 0 & 1 & 8 & 0 & 0 & 0 & 0 & 0 & 2 & 7 & 13 \\
\hline & cmsawles & 1 & 0 & 0 & 1 & 0 & 0 & 0 & 0 & 0 & 0 & 0 & 0 & 0 & 0 & 0 & 2 & 1 & 3 \\
\hline & cmancriw & 54 & 2 & 10 & 8 & 12 & 3 & 0 & 0 & 11 & 5 & 0 & 1 & 0 & 0 & 0 & 2 & 87 & 21 \\
\hline & TOTAL M1 & 68 & 4 & 26 & 11 & 19 & 11 & 0 & 0 & 17 & 35 & 0 & 1 & 0 & 1 & 0 & 14 & 130 & 77 \\
\hline M2 & cmayenbi & 1 & 2 & 0 & 2 & 0 & 1 & 0 & 0 & 0 & 1 & 0 & 1 & 0 & 0 & 0 & 1 & 1 & 8 \\
\hline \multirow[t]{4}{*}{ M3(4) } & cmctmeli & 1 & 10 & 2 & 17 & 0 & 6 & 0 & 0 & 0 & 9 & 0 & 4 & 0 & 0 & 0 & 4 & 3 & 50 \\
\hline & cmetpars & 5 & 30 & 1 & 33 & 0 & 4 & 0 & 2 & 0 & 8 & 0 & 1 & 0 & 0 & 0 & 3 & 6 & 81 \\
\hline & cmvices 4 & 0 & 7 & 0 & 5 & 0 & 1 & 0 & 0 & 0 & 0 & 0 & 1 & 0 & 0 & 0 & 2 & 0 & 16 \\
\hline & $\begin{array}{l}\text { TOTAL } \\
\text { M3(4) }\end{array}$ & 6 & 47 & 3 & 55 & 0 & 11 & 0 & 2 & 0 & 17 & 0 & 6 & 0 & 0 & 0 & 9 & 9 & 147 \\
\hline TOTAL & & 75 & 53 & 29 & 68 & 19 & 23 & 0 & 2 & 17 & 53 & 0 & 8 & 0 & 1 & 0 & 24 & 140 & 232 \\
\hline
\end{tabular}

TABLE 3: The distribution of bare singular (BSG) nominals and nominals with an (AN) in Middle English

(Crisma and Pintzuk 2016: Table 1)

The texts in Table 3 are arranged in chronological order. The columns are arranged left to right in order of increasing saliency of presupposition of existence: there is no presupposition of existence with GNR, NPE, EXS-SCOPE-nrw; there is a clear presupposition of existence with EXS-SCOPE-wd, EXS-SPC; and finally there is a 'gray' area in the middle: EXS-SCOPE-amb, EXS, AMB.

According to Crisma 2015, an develops in three stages in the history of English. In Stage 1, an is the numeral 'one'; in Stage 2, an is an overt 
existential operator used when an indefinite noun phrase is interpreted as specific or when it takes wide scope over another operator; in Stage 3 , an is an expletive used with all singular noun phrases. Crisma notes that in Stages 1 and 2, an is never used with generics.

The numbers are quite small in most of the cells in Table 3; presenting frequencies would be misleading. Nevertheless, clear patterns emerge. We can see that in the M1 period, an acts as an overt existential operator in the following types of nominals: 1) indefinite nominals that are interpreted as specific (EXS-SPC: 0 BSG, $14 \mathrm{AN}$ ); 2) nominals that take wide scope over some other operator (EXS-SCOPE-wd: 0 BSG, $1 \mathrm{AN}$ ). For nominals in the absence of other logical operators, an is favoured by about 2 to 1 over BSG (EXS: $17 \mathrm{BSG}, 35 \mathrm{AN}$ ). For NPE nominals, either generic or narrow scope existential, as well as for existential nominatives taking narrow scope, BSG is favoured by about 2 to 1 over an (EXS SCOPE-nrw: 19 BSG, 11 AN; NPE: 26 BSG, 11 $\mathrm{AN})$. In addition, we also see the first sign of change: in two texts, Ancrene Riwle and Hali Meidhad, there are two examples each of an used with generics (GNR).

In the M3 period, we see a number of changes: 1) for generics (GNR), a sharp reversal in the distribution of BSG (6 BSG, $47 \mathrm{AN}) ; 2$ ) for nominals with no presupposition of existence (NPE), there is also a reversal, with only $3 \mathrm{BSG}$ and $55 \mathrm{AN}$; 3) similarly for existential nominals with narrow scope (EXS-SCOPE-nrw) and existential nominals in the absence of other logical operators (EXS), with all 11 and 17 tokens, respectively, using AN. Our conclusion is that in this period, the use of an with singular nouns has generalised to all contexts, with very few exceptions.

\section{Method 3: Embedding information in coding strings}

Coding strings are strings of characters, each character representing a linguistic or extralinguistic variable, which are inserted as nodes in the tokens of a corpus file. Method 3, the construction of coding strings, is the traditional and perhaps most widely used method of adding information to corpus data. Coding strings had their origin in quantitative sociolinguistic research and were used decades before the creation of parsed corpora. The CODING function of CS is used to construct coding strings based on the morphosyntactic annotation and the lexical content of the token; once created, coding strings may be manually extended to encode information that is not represented in the corpus. Since coding strings are part of the token structure, they may be searched and manipulated by CS. Coding strings may also be used 
as input to software for statistical analysis, like R; this is perhaps their most important function.

Case study 3: Taylor and Pintzuk 2015 (T\&P 2015) examine the position of objects in Old English and look at the effect of verb order and the length and information structure of the object to support their conclusion that there are two sources for post-verbal objects in Old English, object postposition and base-generation. As shown in (4) below, objects can appear both before and after the verb cluster in clauses with non-finite main verbs before finite auxiliaries $(\mathrm{O} V$ Aux and $\mathrm{V}$ Aux O), and before and after non-finite verbs in clauses with auxiliary - main verb order (Aux O V and Aux V O). In these examples, finite auxiliaries are underlined, non-finite main verbs are italicised, and objects are in bold face.

a. $\mathrm{O} \mathrm{V}$ Aux

gif heo pæt bysmor forberan wolde

if she that disgrace tolerate would

'if she would tolerate that disgrace'

(coaelive,+ALS_[Eugenia]:185.305)

b. V Aux O

pæt he friðian wolde ba leasan wudewan

that he make-peace-with would the false widow

'that he would make peace with the false widow'

(coaelive,+ALS_[Eugenia]:209.315)

c. Aux O V

purh ba heo sceal hyre scippend understandan

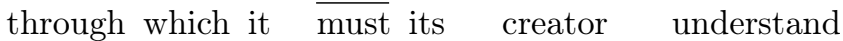

'through which it must understand its creator'

(coaelive,+ALS_[Christmas]:157.125)

d. Aux V O

swa pæet heo bið forloren bam ecan life

so that it is lost the eternal life

'so that it is lost to the eternal life'

(coaelive, +ALS_[Christmas]:144.117)

Table 4 shows the distribution of objects in Old English texts that have more than 100 clauses with finite auxiliaries, non-finite main verbs

\footnotetext{
${ }^{5}$ There are additional constraints on the object; see T\&P 2015.
} 
and non-pronominal objects. ${ }^{5}$

\begin{tabular}{|l|r|r|r|r|}
\hline \multirow{2}{*}{ Text } & \multicolumn{2}{|c|}{ VAux } & \multicolumn{2}{c|}{ AuxV } \\
\cline { 2 - 5 } & N & \multicolumn{1}{|c|}{ \%VO } & \multicolumn{1}{c|}{ N } & \multicolumn{1}{c|}{ \% VO } \\
\hline Orosius & 66 & 4.5 & 47 & 31.9 \\
\hline Bede & 58 & 6.9 & 46 & 10.9 \\
\hline Boethius & 74 & 8.1 & 49 & 53.1 \\
\hline Cura Pastoralis & 51 & 21.6 & 72 & 55.6 \\
\hline Catholic Homilies I & 49 & 10.2 & 95 & 47.4 \\
\hline Catholic Homilies II & 42 & 7.1 & 80 & 46.3 \\
\hline Lives of Saints & 33 & 45.5 & 91 & 62.6 \\
\hline Gregory's Dialogues (C) & 36 & 27.8 & 66 & 68.2 \\
\hline total & 409 & 13.9 & 546 & 49.5 \\
\hline
\end{tabular}

TABLE 4: Frequency of VO order by verb order in texts with more than 100 tokens

(T\&P 2015, Table 1)

T\&P 2015 present the following analysis of these data. They assume that in the Old English period, there was variation in underlying structure: head-initial/final IPs (AuxV/VAux) and VPs (VO/OV). V Aux $\mathrm{O}$ can be derived only from head-final IP/VP structure by postposition of $\mathrm{O}$ from preverbal position, as shown in (5)a-b. In contrast, Aux V O order can be derived in two different ways: a) head-initial IP, head-final VP structure with postposition of $\mathrm{O}$, as shown in (5)c-d; b) head-initial $\mathrm{IP} / \mathrm{VP}$ structure (i.e. $\mathrm{O}$ is merged in post-verbal position), as shown in (5)e.

(5) a. O V Aux: $\left[\mathrm{TP} \ldots\left[\mathrm{T}^{\prime}\left[\mathrm{vP} 1[\mathrm{vP} 2 \mathrm{O}\right.\right.\right.$ V $\left.\left.\left.] \mathrm{t}_{\mathrm{Aux}}\right] \mathrm{Aux}+\mathrm{T}\right]\right]$

b. V Aux O: $\left.\left[\mathrm{TP}^{\mathrm{T}} \ldots \mathrm{T}_{\mathrm{T}^{\prime}}\left[\mathrm{VP}_{\mathrm{VP}}\left[\mathrm{VP}_{2} \mathrm{t}_{\mathrm{O}} \mathrm{V}\right] \mathrm{t}_{\mathrm{Aux}}\right] \mathrm{Aux}+\mathrm{T}\right] \mathrm{O}\right]$

c. Aux O V: $\left[\mathrm{TP} \ldots\left[\mathrm{T}^{\prime} \operatorname{Aux}+\mathrm{T}\left[\mathrm{vp}_{\mathrm{vP}} \mathrm{t}_{\mathrm{Aux}}[\mathrm{vP2} \mathrm{O} \mathrm{V}]\right]\right]\right]$

d. Aux V O: $\left[\mathrm{TP} \ldots\left[_{\mathrm{T}^{\prime}} \operatorname{Aux}+\mathrm{T}\left[\mathrm{vp}_{\mathrm{vp}} \mathrm{t}_{\mathrm{Aux}}\left[\mathrm{vp}_{2} \mathrm{t}_{\mathrm{O}} \mathrm{V}\right]\right]\right] \mathrm{O}\right]$

e. Aux V O: $\left[\mathrm{TP} \ldots\left[\mathrm{T}^{\prime} \operatorname{Aux}+\mathrm{T}\left[\mathrm{vp}_{\mathrm{v} 1} \mathrm{t}_{\mathrm{Aux}}[\mathrm{vp2} \mathrm{V}\right.\right.\right.$ O $\left.\left.\left.]\right]\right]\right]$

If all post-verbal objects were derived by postposition in both $\mathrm{V}$ Aux and Aux V clauses, i.e. if structure (5)e didn't exist, we would expect the factors influencing post-verbal position to be the same in both clause types. To test this null hypothesis, T\&P 2015 looked at the influence of weight (as measured by the length of the object in words) and informational status (given vs. new) on the position of objects in AuxV and VAux clauses. This was a four-step process. As a first step, CS was used to code each token for three factors: the order of finite 
auxiliary and non-finite main verb (auxv vs. vaux); the position of the object with respect to the non-finite main verb (ov vs. vo); the length of the object in words $(1 \ldots 11)$. The coding query file is given below in $(6) ;^{6}$ an example of a token coded for the first three factors is given in $(7)$.

\section{(6) Coding Query:}

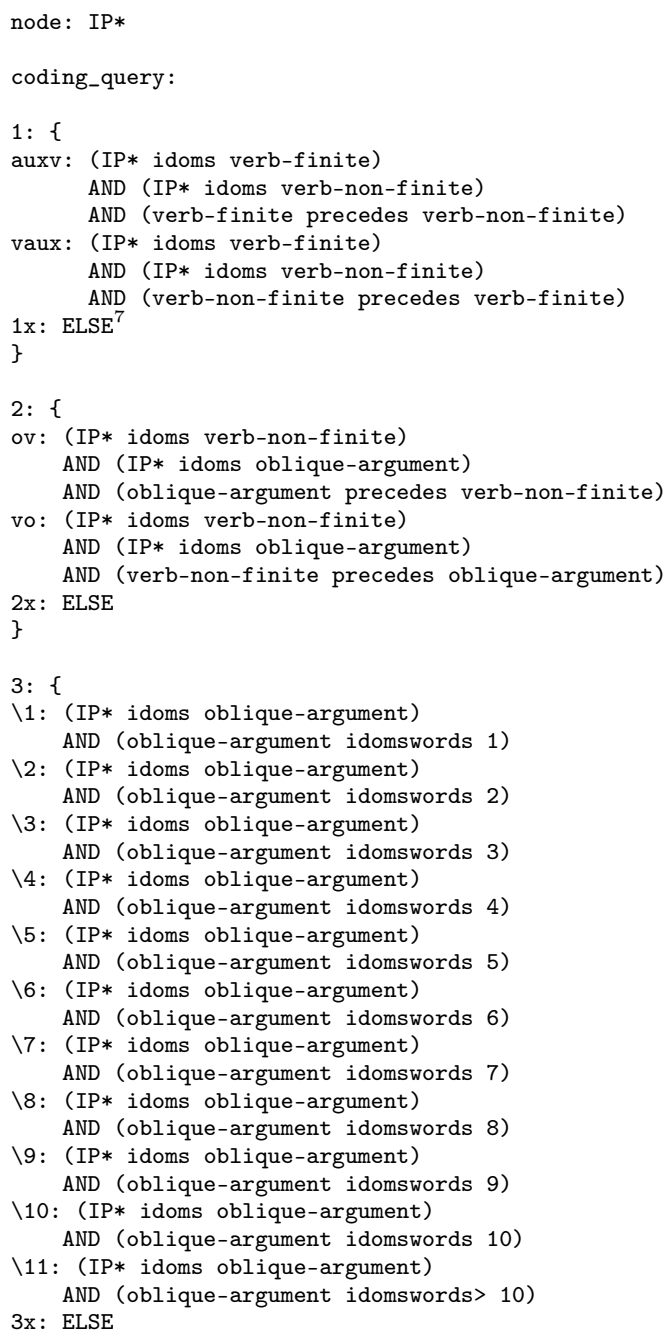

${ }^{6}$ The terms 'verb-finite', 'verb-non-finite', and 'oblique-argument' are defined in a condition file, available to CS when queries are run. 


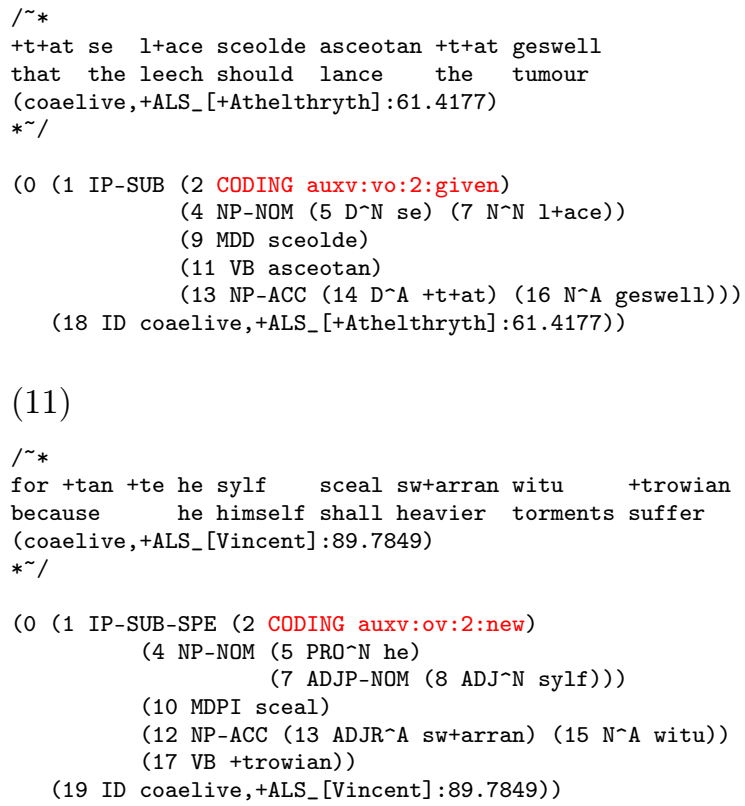

The third step was to use the print_only function of CS to create an output file containing only the coding strings of the data file. The file is shown in (12) below. CS separates the factors by ':', and the user must manually insert a header naming the factors for input to statistical processing, the last step. The results for this study are shown in Table 5 .

(12) file of coding strings

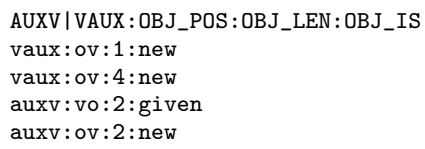

As shown in Table 5, the effect of weight is significant in both clause types, but slightly weaker in AuxV clauses: each additional word in VAux clauses increases the likelihood of VO order by 2.68, in AuxV clauses by 2.43. Informational status is significant only in VAux clauses: the distance between given and new is .9 in VAux clauses, but only .08 in AuxV clauses. T\&P 2015 interpret these results as follows: VAuxO clauses are derived only by postposition of the object, and postposition is strongly influenced by weight and informational status: heavy objects 


\begin{tabular}{|l|l|c|c|c|c|}
\hline \multirow{2}{*}{ Variable } & \multirow{2}{*}{ Level } & \multicolumn{2}{|c|}{ V Aux O } & \multicolumn{2}{c|}{ Aux V O } \\
\cline { 3 - 6 } & & Log odds & Odds ratio & Log odds & Odds ratio \\
\hline weight & per additional word & 0.99 & 2.68 & 0.89 & 2.43 \\
\hline info status & given & -0.45 & 0.64 & -0.04 & 0.96 \\
\hline & new & 0.45 & 1.57 & 0.04 & 1.04 \\
\hline
\end{tabular}

VAuxO: $\mathrm{C}=0.88$; AuxVO: $\mathrm{C}=0.78$

TABLE 5: Results of multivariate analysis, effects in log odds and odds ratios. Shaded cells indicate non-significant results

(from T\&P 2015, Table 5)

and new objects are much more likely to postpose than light objects and given objects. Since AuxVO clauses are derived by two different processes, postposition and base-generation, the effects of weight and informational status are weakened; this is why the effect of weight is weaker in $\mathrm{AuxV}$ clauses and the effect of informational status is reduced to non-significance.

\section{Method 4: Modifying corpus annotation (node labels and structure)}

Method 4, the modification of corpus annotation, may be done manually, but it is much more efficient (and safer) to use the corpus-revision tool of CS. This tool enables the addition, deletion, and modification of annotation in the corpus, including not only node labels but also structure. Any search that can be made using CS can act as the basis for corpus revision; the output of corpus revision is a new version of the corpus - i.e., the original version of the corpus is not deleted, in case of catastrophic errors. Corpus revision can be used to build an annotated corpus starting from a straight text corpus with only part-of-speech. I frequently find it useful to mark particular structures so that they are easy to identify, and also to evade some CS restrictions, as will be seen in Case study 4 below.

Case study 4: Haeberli and Pintzuk 2017 (H\&P) look at verb placement in 'true V2' contexts in Old English. H\&P analyse in detail one particular clause type: clauses with an initial gif/ba/ponne 'if/when/ when' subordinate clause, followed by a resumptive adverb (e.g. $p a$ / ponne 'then') and the rest of the main clause; an example is given in (13). Note that initial pa/ponne in Old English main clauses is considered a 'true V2' context: $97.4 \%$ (6546/6719) of these clauses exhibit strict V2 order, with the verb in second position followed by the subject. 
[IP-MAT [CP-ADV pa [IP-SUB pæet Placidas geseah]], pa
When that Placidas saw, then

gewilnode he [CP-THT bæt [IP-SUB he hine gefenge]]]

wanted he that he it took

'When Placidas saw that, then he wanted to take it'

(coeust,LS_8_[Eust]:31.26)

In order to simplify the searches for and coding of these clauses, I wanted to flag the relevant IP-MATs and CP-ADVs by modifying the label. In addition, I wanted to 'remove' ${ }^{8}$ the subtrees of all subordinate clauses other than the IP-SUB dominated by the relevant CP-ADV. Three steps were necessary, as shown below; a red font is used for highlighting.

Step 1: Flag the relevant IP-MAT, CP-ADV, and IP-SUB using the query file below. The IP-MAT and CP-ADV are flagged by appending '- $z$ ' to the label; the IP-SUB is flagged by prepending ' $\mathrm{x}-$ ' to the label. Notice that the first token (coeust ... 26) contains an IP-SUB that is not dominated by the clause-initial CP-ADV; the second token (cobede ... 3530) contains an IP-MAT that does not dominate a CP-ADV as the first constituent; and the third token (cocanedgX . . 8 82) contains both a CP-ADV that is not the first constituent of the IP-MAT and an IP-SUB that is not dominated by the relevant CP-ADV. These are all nodes that are irrelevant to the investigation.

\section{Step 1 Query:}

node: IP-MAT*

nodes_only: $t$

remove_nodes: $f$

query: ( $\{1\}$ IP-MAT* idoms $\{2\} \mathrm{CP}-\mathrm{ADV} *$ )

AND (CP-ADV* idoms $P$ )

AND ( $P$ idoms GIF $\mid$ THA $\mid$ THONNE $^{9}$ )

AND (CP-ADV* idoms $\{3\}$ IP $*$ SUB $*$ )

..

append_label\{1\}: $-z$

append_label $\{2\}:-z$

prepend_label $\{3\}: \mathrm{x}-$

\footnotetext{
${ }^{8}$ Setting the CS command-file option 'remove nodes' to true results in removing recursive structure by removing the subtrees of all nodes that are a) embedded within an instance of the 'node' setting and b) are of the same type as the 'node' setting. The subtrees are replaced by the label 'RMV' and the first three lexical words of the node.

${ }^{9} \mathrm{GIF}$, THA and THONNE are defined in a condition file as all of the variant spellings of these lexemes.
} 


\section{Step 1 Input:}

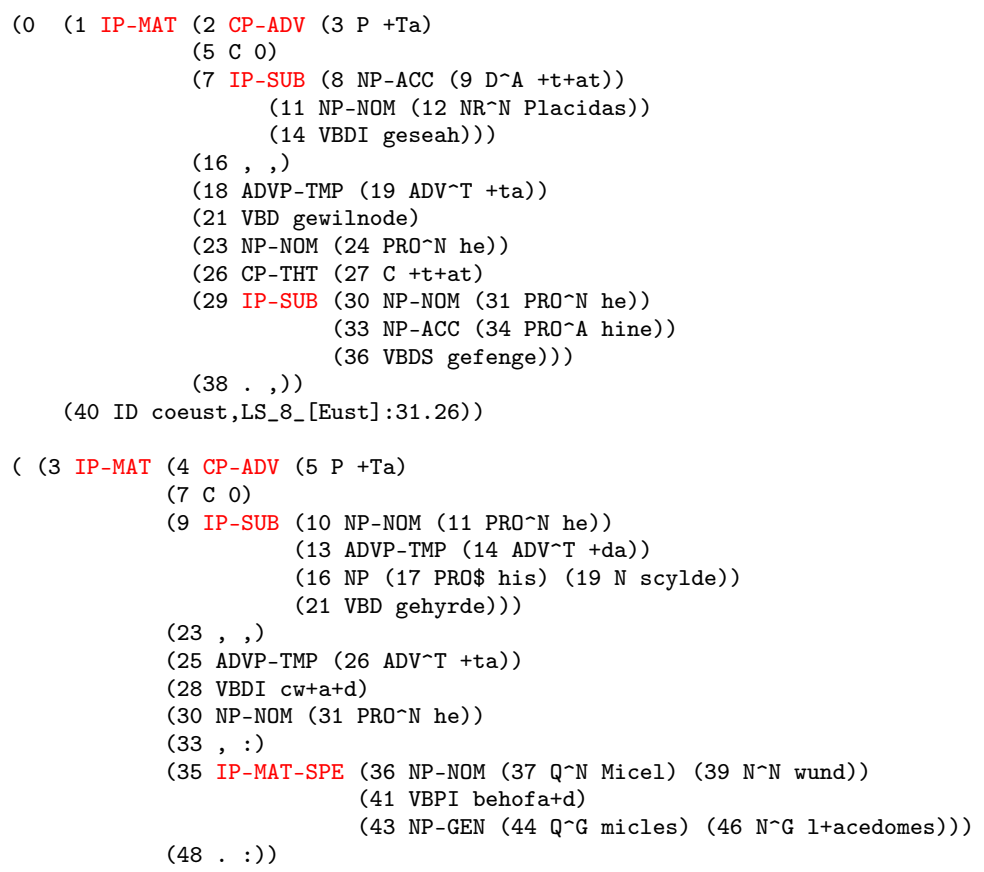

(50 ID cobede, Bede_4:26.350.19.3530))

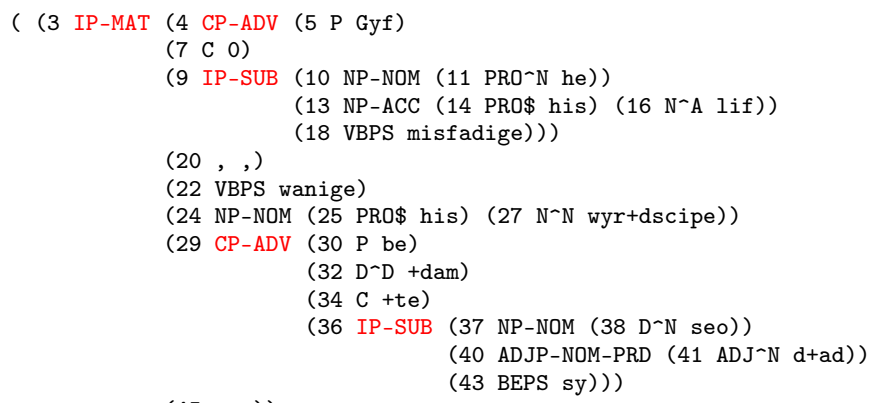

(47 ID cocanedgX, WCan_1.1.2_[Fowler] :68.82))

\section{Step 1 Output:}

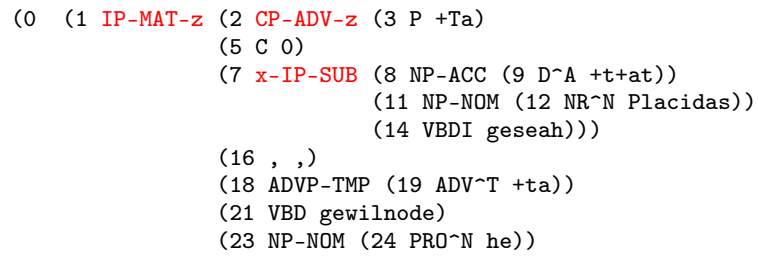




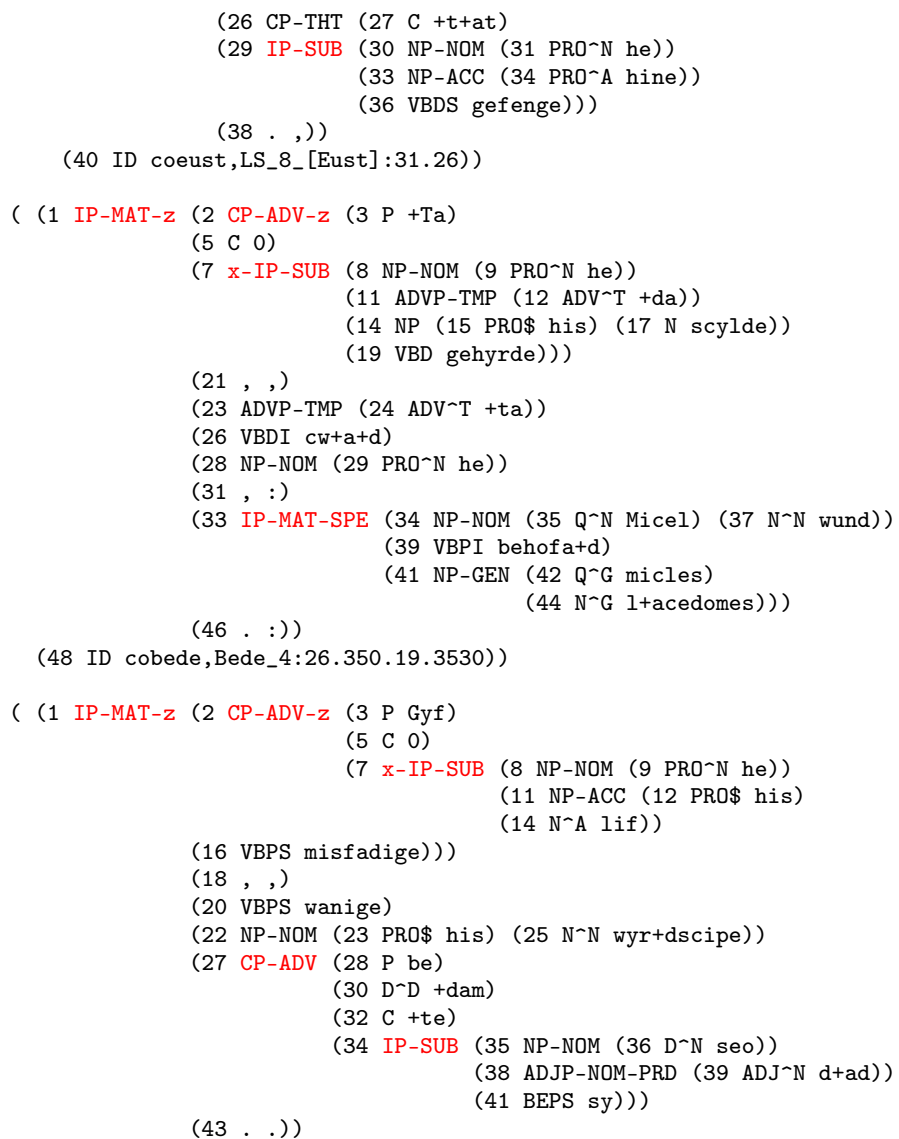

(45 ID cocanedgX, WCan_1.1.2_[Fowler] :68.82))

Step 2: Remove the nodes of the embedded IPs using the query file below; the output from Step 1 serves as the input to Step 2. Note that the nodes of the IP-SUB embedded under CP-ADV-z are not removed since its label begins with ' $\mathrm{x}-$ '.

\section{Step 2 Query:}

node: IP-MAT*-z

remove_nodes: $t$

query: (IP-MAT*-z exists)

\section{Step 2 Output:}

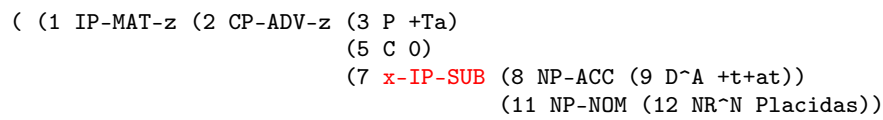




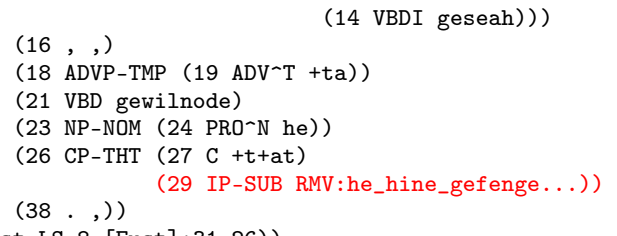

(40 ID coeust,LS_8_[Eust]:31.26))

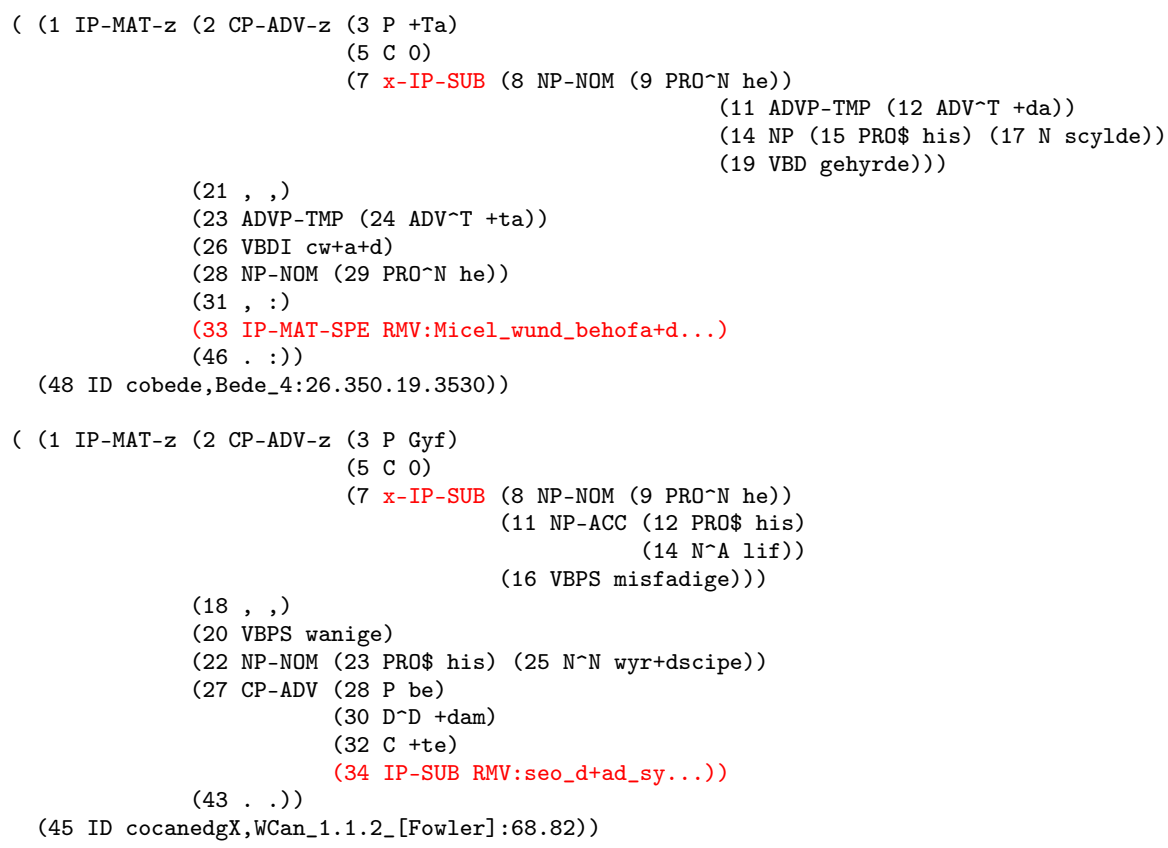

(45 ID cocanedgX, WCan_1.1.2_[Fowler] :68.82))

Step 3: Remove ' $\mathrm{x}$-' prepended to IP-SUB labels using the query file below; the output from Step 2 serves as the input to Step 3.

\section{Step 3 Query:}

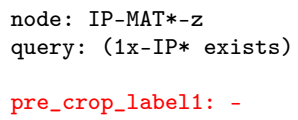

\section{Step 3 Output:}

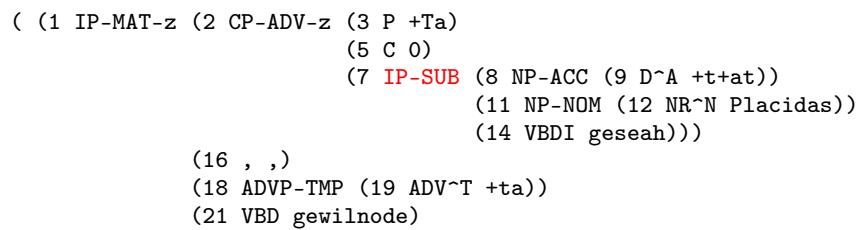




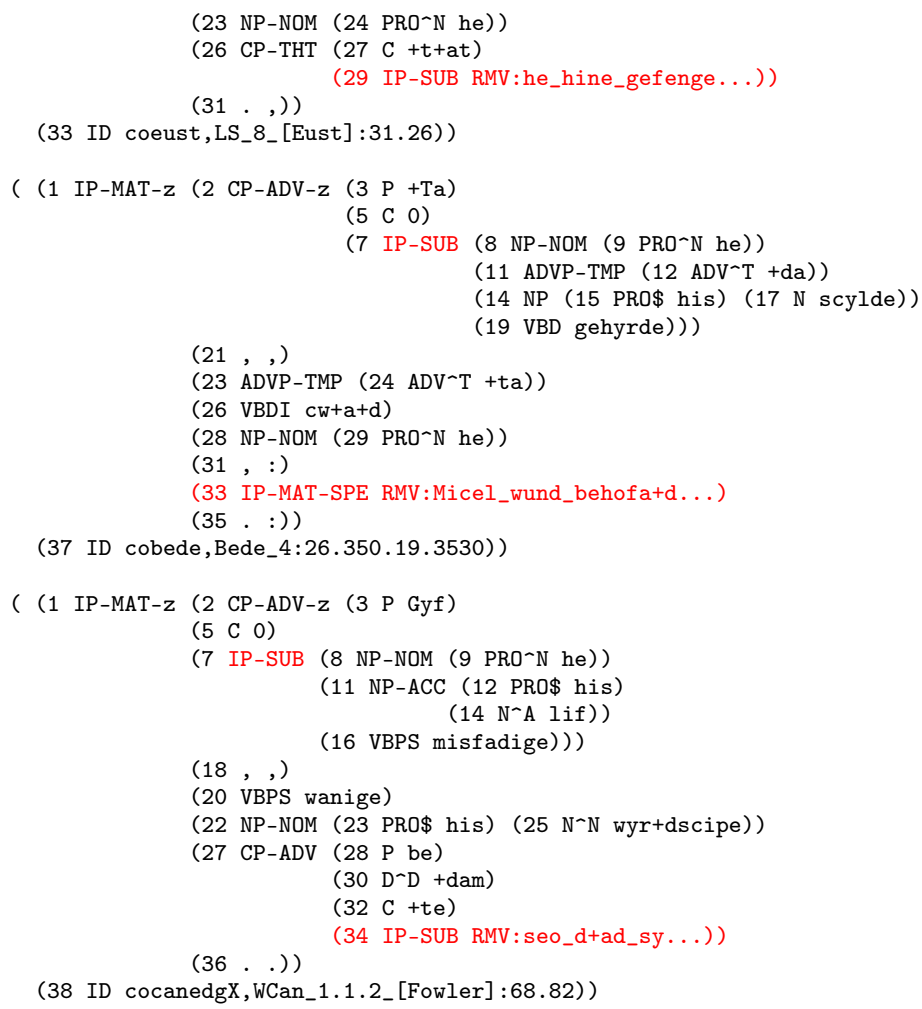

The result of this three-step procedure is a file of tokens that are simple to search further and code, since the relevant IP-MATs and CPADVs have labels that end in '-z' and the relevant IP-SUB is the only IP-SUB in the token that has its content preserved intact.

\section{Method 5: Copying coding strings from the corpus into a spreadsheet}

Finally, Method 5 copies coding strings from the corpus into a spreadsheet, the content of which may be ordered, manipulated, and displayed in ways that corpus data cannot be. For example, the data in the cells of a spreadsheet can be interpreted as numbers and used for simple calculations like totals, means, and frequencies; in contrast, the content of coding strings within a corpus are characters, not numerical values, and cannot be used as numbers. From the spreadsheet users can create output, e.g. a csv file, that is formatted for statistical analysis. Method 5 provides perhaps the most flexible way of working with and analyzing corpus data, but it should be used with caution, for at least two obvi- 
ous reasons: it involves manual manipulation of the data, and therefore is prone to error; in addition, it is not always possible to go from a spreadsheet back to a corpus format.

Case study 5: Taylor and Pintzuk 2017 (T\&P 2017) look at the effect of weight, among other variables, on split coordination in Old English. Almost all coordinated constituents in early stages of English can be split, as illustrated in (14).

a. DP subject

oðpæt pæt ad wæs forburnen, and ealle pa tunnan until the pile was burned and all the casks

'until the pile and all the casks were burned up'

(coaelive,+ALS_[Julian_and_Basilissa]:332.1143)

b. DP object

God sende ðа fyr on merigen and fulne swefel

God sent then fire in morning and foul brimstone

him to

him to

'God then sent fire and foul brimstone to him in the morning' (coaelive, + ALS$\left[\mathrm{Pr} \_\right.$Moses]:211.2976)

c. PP

\& on sorhge leofodon \& on geswincum sippan and in grief lived and in torment afterwards 'and [they] lived afterwards in grief and torment' (colsigewZ,+ALet_4_[SigeweardZ]:117.49)

T\&P 2017 focus on subjects, aiming to measure the effect of length (as measured in number of words) on splitting. They need the length of the first conjunct, the length of the second conjunct (which includes both the conjunction and the nominal), and the length of the entire coordinated nominal in order to determine which of the three, if any, has an effect on splitting. But because of the way coordination is annotated in the corpus, these measurements are not at all straightforward.

If the nominal is not split and the coordinated nouns are bare, with no modification, then the nominal is annotated as a flat structure, with the two nouns and the conjunction immediately dominated by the NP, as shown in (15). In these cases the length of the entire subject can be measured, since it is a constituent (NP-NOM). Although the lengths of the two conjuncts can't be measured individually, since they are not 
constituents, it can be assumed that the length of the first conjunct is $1 .{ }^{10}$ The tokens in this section are coded as follows: file name : token number : flat vs. non-flat : split vs. non.split : final vs. non.final (position within the clause) : length of $1^{\text {st }}$ conjunct : length of $2^{\text {nd }}$ conjunct: length of entire conjoined phrase. '/' is used when it is not possible to measure or assume the length.

non-split flat structure

Pær is wop and wanung

There is weeping and wailing

(coaelive,+ALS_[Sebastian]:77.1254)

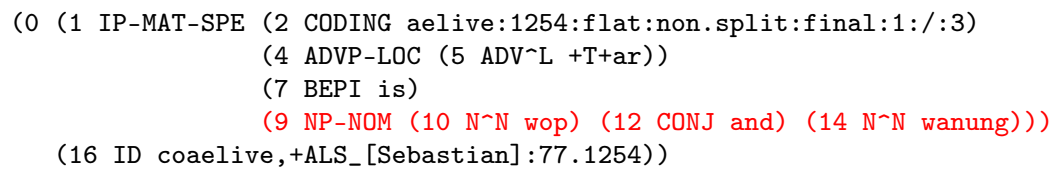

In split flat structures, we can measure the length of the $1^{\text {st }}$ conjunct and the length of the $2^{\text {nd }}$ conjunct, since each of these is a constituent; but we cannot measure the length of the entire subject. An example is given in (16).

(16) split 'flat' structure

ac foxunga wæron wunigende on him, and upahefednys but foxlike-wiles were dwelling in him, and haughtiness, swilce healice fugelas, like soaring birds,

'but foxlike wiles and haughtiness were dwelling in him, like soaring birds'

(coaelive,+ALS_[Memory_of_Saints]:160.3418)

\footnotetext{
${ }^{10}$ The reader might think that the length of the $2^{\text {nd }}$ conjunct could be estimated as 2 (conjunction + noun). However, some conjoined constituents have more than two conjuncts, as shown below in (i); in these cases, the length of the $2^{\text {nd }}$ and following conjuncts cannot be assumed or measured.
}

(i)

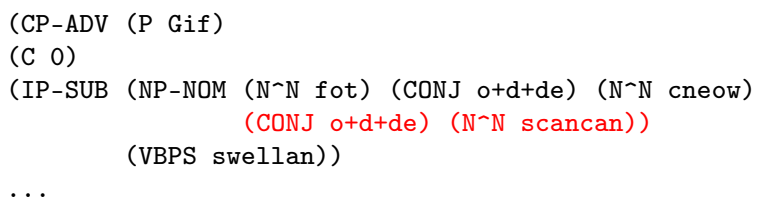


(0 (1 IP-MAT (2 CODING aelive:3418:flat:split:non.final:1:2:/)

(4 CONJ ac)

(6 NP-NOM ( $7 \mathrm{~N}^{\wedge} \mathrm{N}$ foxunga)

(11 BEDI w+aron)

(9 CONJP $* \mathrm{ICH} *-1)$ )

(13 VAG wunigende)

(15 PP (16 P on)

$(21,$,

(18 NP-DAT (19 PRO^D him)))

(23 CONJP-1 (24 CONJ and) (26 $\mathrm{N}^{\wedge} \mathrm{N}$ upahefednys))

(28 PP (29 P swilce)

$(34,)$,

(31 CPX-CMP (32 IPX-SUB RMV:healice_fugelas...)))

(36 ID coaelive,+ALS_[Memory_of_Saints]:160.3418))

In non-split non-flat structures, we can measure all three, since the two conjuncts and also the entire conjoined structure is a constituent, as shown in (17).

(17) non-split hierarchical structure

Eubolus se uðwyta and pa yldostan preostas stoden Eubolus the philosopher and the principal priests stood æet pæra dura

at the door ...

(coaelive,+ALS_[Basil]:132.537)

(0 (1 IP-MAT (2 CODING aelive:537:non.flat:non.split:non.final:3:4:7)

(4 NP-NOM (5 NP-NOM ( 6 NR^N Eubolus)

(8 NP-NOM-PRN (9 $\mathrm{D}^{\sim} \mathrm{N}$ se)

(11 $\mathrm{N}^{\wedge} \mathrm{N} \mathrm{u+dwyta)))}$

(13 CONJP (14 CONJ and)

(16 NP-NOM (17 $\left.\mathrm{D}^{\wedge} \mathrm{N}+\mathrm{ta}\right)$

(19 ADJS $^{\wedge} \mathrm{N}$ yldostan)

(23 VBDS stoden)

$\left(21 \mathrm{~N}^{\wedge} \mathrm{N}\right.$ preostas))))

(25 PP $(26 \mathrm{P}+\mathrm{at})$

(28 NP-DAT (29 $\mathrm{D}^{\wedge} \mathrm{D}+\mathrm{t}+$ ara $)\left(31 \mathrm{~N}^{\wedge} \mathrm{D}\right.$ dura $\left.\left.)\right)\right)$

...

(48 ID coaelive,+ALS_[Basil]:132.537))

And finally, in split hierarchical structures, we can measure the length of the $1^{\text {st }}$ conjunct and the length of the $2^{\text {nd }}$ conjunct, since each of these is a constituent; but we cannot measure the length of the entire subject. An example is given in (18).

(ID colacnu,Med_3_[Grattan-Singer]:85.1.454)) (CP-ADV (P Gif) 
(18) split hierarchical structure

oðpæt pæt ad wæs forburnen, and ealle pa tunnan

until the pile was burned-up, and all the tuns

(coaelive,+ALS_[Julian_and_Basilissa]:332.1143)

(0 (1 IP-SUB (2 CODING aelive:1143:non.flat:split:final:2:4:/)

(4 NP-NOM (5 NP-NOM (6 $\left.\mathrm{D}^{\sim} \mathrm{N}+\mathrm{t}+\mathrm{at}\right)\left(8 \mathrm{~N}^{\wedge} \mathrm{N}\right.$ ad))

(10 CONJP $* \mathrm{ICH} *-1)$ )

(12 BEDI w+as)

(14 VBN forburnen)

$(16,$,

(18 CONJP-1 (19 CONJ and)

(21 NP-NOM (22 Q^N ealle)

$\left(24 \mathrm{D}^{\sim} \mathrm{N}+\mathrm{ta}\right)\left(26 \mathrm{~N}^{\sim} \mathrm{N}\right.$ tunnan)) ))

(28 ID coaelive,+ALS_[Julian_and_Basilissa]:332.1143))

Once the tokens are coded in this way, CS can be used to output the coding strings to a file as shown below:

\section{Query:}

node: $\$$ ROOT $^{11}$

print_only: CODING*

\section{Input:}

(0 (1 IP-MAT-SPE (2 CODING aelive:1254:flat:non.split:final:1:/:3)

(4 ADVP-LOC (5 ADV^L +T+ar))

(7 BEPI is)

(9 NP-NOM (10 $\mathrm{N}^{\wedge} \mathrm{N}$ wop) (12 CONJ and) (14 $\mathrm{N}^{\wedge} \mathrm{N}$ wanung)))

(16 ID coaelive,+ALS_ [Sebastian]:77.1254))

(0 (1 IP-MAT (2 CODING aelive:3418:flat:split:non.final:1:2:/)

(4 CONJ ac)

(6 NP-NOM ( $7 \mathrm{~N}^{\wedge} \mathrm{N}$ foxunga)

(11 BEDI w+aron)

(9 CONJP $*$ ICH $*-1)$ )

(13 VAG wunigende)

(15 PP (16 P on)

$(21,$,

(18 NP-DAT (19 PRO^D him)))

(23 CONJP-1 (24 CONJ and) (26 $\mathrm{N}^{\wedge} \mathrm{N}$ upahefednys))

(28 PP (29 P swilce) $(34,)$,

(31 CPX-CMP (32 IPX-SUB RMV:healice_fugelas...)))

(36 ID coaelive,+ALS_[Memory_of_Saints] :160.3418))

\footnotetext{
${ }^{11}$ The node \$ROOT is used to refer to the highest node in the token.
} 
(0 (1 IP-MAT (2 CODING aelive:537:non.flat:non.split:non.final:3:4:7)

(4 NP-NOM (5 NP-NOM ( 6 NR^N Eubolus)

(8 NP-NOM-PRN (9 D^N se)

(13 CONJP (14 CONJ and)

(11 $\mathrm{N}^{\wedge} \mathrm{N}$ u+dwyta)))

(16 NP-NOM (17 D^N +ta)

(19 ADJS $^{\wedge} \mathrm{N}$ yldostan)

(21 $\mathrm{N}^{\wedge} \mathrm{N}$ preostas))))

(23 VBDS stoden)

(25 PP (26 P +at)

(28 NP-DAT (29 $\mathrm{D}^{\wedge} \mathrm{D}+\mathrm{t}+$ ara) $\left(31 \mathrm{~N}^{\wedge} \mathrm{D}\right.$ dura $\left.\left.)\right)\right)$

...

(48 ID coaelive,+ALS_[Basil]:132.537))

(0 (1 IP-SUB (2 CODING aelive:1143:non.flat:split:final:2:4:/)

(4 NP-NOM (5 NP-NOM (6 $\left.\mathrm{D}^{\wedge} \mathrm{N}+\mathrm{t}+\mathrm{at}\right)\left(8 \mathrm{~N}^{\wedge} \mathrm{N}\right.$ ad))

(10 CONJP $* \mathrm{ICH} *-1)$ )

(12 BEDI w+as)

(14 VBN forburnen)

$(16,$,

(18 CONJP-1 (19 CONJ and)

(21 NP-NOM (22 Q^N ealle)

$\left(24 \mathrm{D}^{\wedge} \mathrm{N}+\mathrm{ta}\right)\left(26 \mathrm{~N}^{\wedge} \mathrm{N}\right.$ tunnan $\left.\left.\left.)\right)\right)\right)$

(28 ID coaelive,+ALS_[Julian_and_Basilissa]:332.1143))

\section{Output:}

aelive: $1254:$ flat:non.split:final $: 1: /: 3$

aelive:3418:flat:split:non.final: $1: 2: /$ )

aelive:537:non.flat:non.split:non.final:3:4:7)

aelive:1143:non.flat:split:final: $2: 4: /$ )

The output file can then be read into a spreadsheet, as shown below in Excel spreadsheet 1, with the header ("TEXT | TOKEN | (NON)FLAT | ..") added manually as the first row. When the data are sorted by the missing length, as shown in spreadsheet 2 , then the formulae for the missing lengths can be inserted manually in the empty cells, as shown in spreadsheet 3 .

Excel spreadsheet 1: coding strings read from the CS output file, with header added

\begin{tabular}{|l|l|r|l|l|l|r|r|r|}
\hline & \multicolumn{1}{|c|}{ A } & \multicolumn{1}{c|}{ B } & \multicolumn{1}{c|}{ C } & \multicolumn{1}{c|}{ D } & \multicolumn{1}{c|}{ E } & \multicolumn{1}{c|}{ F } & \multicolumn{1}{c|}{ G } & \multicolumn{1}{c|}{ H } \\
\hline & TEXT & TOKEN & (NON)FLAT & (NON)SPLIT & (NON)FINAL & LEN(C1) & LEN(C2) & LEN(C1+C2) \\
\hline 1 & aelive & 1254 & flat & non.split & final & 1 & & 3 \\
\hline 2 & aelive & 3418 & flat & split & non.final & 1 & 2 & \\
\hline 3 & aelive & 537 & non.flat & non.split & non.final & 3 & 4 & \\
\hline 4 & aelive & 1143 & non.flat & split & final & 2 & 4 & \\
\hline 5 & $\ldots$ & & & & & & & \\
\hline
\end{tabular}


Excel spreadsheet 2: coding strings sorted by which length is missing

\begin{tabular}{|l|l|r|l|l|l|r|r|r|}
\hline & \multicolumn{1}{c|}{ A } & \multicolumn{1}{c|}{ B } & \multicolumn{1}{c|}{ C } & \multicolumn{1}{c|}{ D } & \multicolumn{1}{c|}{ E } & \multicolumn{1}{c|}{ F } & \multicolumn{1}{c|}{ G } & \multicolumn{1}{c|}{ H } \\
\hline & TEXT & TOKEN & (NON)FLAT & (NON)SPLIT & (NON)FINAL & LEN(C1) & LEN(C2) & LEN(C1+C2) \\
\hline 1 & aelive & 537 & non.flat & non.split & non.final & 3 & 4 & 7 \\
\hline 2 & aelive & 1254 & flat & non.split & final & 1 & & 3 \\
\hline 3 & aelive & 3418 & flat & split & non.final & 1 & 2 & \\
\hline 4 & aelive & 1143 & non.flat & split & final & 2 & 4 & \\
\hline 5 & $\ldots$ & & & & & & & \\
\hline
\end{tabular}

Excel spreadsheet 3: coding strings with formulae for missing length

\begin{tabular}{|c|c|c|c|c|c|c|c|c|}
\hline & A & B & C & D & $\mathrm{E}$ & $\mathrm{F}$ & G & $\mathrm{H}$ \\
\hline 1 & TEXT & TOKEN & (NON)FLAT & (NON)SPLIT & $(\mathrm{NON}) \mathrm{FINAL}$ & LEN(C1) & LEN(C2) & $\operatorname{LEN}(\mathrm{C} 1+\mathrm{C} 2)$ \\
\hline 2 & aelive & 537 & non.flat & non.split & non.final & 3 & 4 & 7 \\
\hline 3 & aelive & 1254 & flat & non.split & final & 1 & $=\mathrm{H} 3-\mathrm{F} 3$ & 3 \\
\hline 4 & aelive & 3418 & flat & split & non.final & 1 & 2 & $=\mathrm{F} 4+\mathrm{G} 4$ \\
\hline 5 & aelive & 1143 & non.flat & split & final & 2 & 4 & $=F 5+G 5$ \\
\hline 6 & & & & & & & & \\
\hline
\end{tabular}

Once the missing lengths have been calculated in the Excel spreadsheet 3 above, it is straightforward to calculate the average length of the $1^{\text {st }}$ conjunct, $2^{\text {nd }}$ conjunct and complete subject by sorting on column D and then adding the lengths of the split / non-split subjects and dividing by the total number of these tokens. T\&P 2017 found that in the Old English data, the average total length of the coordination was 6.88 for split subjects and 5.99 for non-split subjects, a statistically significant difference. Similarly, the average length of the $2^{\text {nd }}$ conjunct was 5.06 for split subjects and 4.08 for non-split subjects; again, a statistically significant difference. But for the $1^{\text {st }}$ conjunct, the average length of the split subjects was less than the average length of the non-split subjects: 1.82 vs. 1.92 .

\section{Conclusions}

In this article I have described and illustrated five methods for adding information to corpora that have been parsed in the Penn treebank style. These methods may involve manual operations, or they may be executed by CS functions, or they may require a combination of manual and automated procedures. Some of the methods overlap: for example, method 2 (inserting CODE nodes) is functionally equivalent to method 3 (embedding information in coding strings). Which method is used depends almost entirely on the type of information to be added and the goals of the user. 


\section{Acknowledgements}

This paper was presented at the international symposium entitled "Exploiting Parsed Corpora: Application in Research, Pedagogy, and Processing" held at the National Institute for Japanese Language and Linguistics (NINJAL) on December 9-10, 2017. I thank the organizers for inviting me to that symposium, the audience for questions and comments, two anonymous reviewers for helpful suggestions, and all of my co-authors for giving me the opportunity to participate in so many interesting research projects.

\section{References}

Crisma, P. 2015. The 'indefinite article' from cardinal to operator to expletive. In A. J. Gianollo, C. and D. Penka, eds., Language Change at the Syntax-Semantics Interface, 125-151. Berlin: De Gruyter Mouton.

Crisma, P. and S. Pintzuk. 2016. An from Old to Middle English. In S. Vikner, H. Jørgensen, and E. van Gelderen, eds., Let Us Have Articles Betwixt Us: Papers in Historical and Comparative Linguistics in Honour of Johanna L. Wood, 31-53. Aarhus: Department of English, School of Communication and Culture, Aarhus University.

Frascarelli, M. and R. Hinterhölzl. 2007. Types of topics in German and Italian. In K. Schwabe and S. Winkler, eds., On Information Structure, Meaning and Form: Generalizations across Languages, 87-116. Amsterdam: John Benjamins.

Frey, W. 2006a. Contrast and movement to the German prefield. In V. Molnár and S. Winkler, eds., The Architecture of Focus (Studies in Generative Grammar 82), 235-264. Berlin, New York: Mouton de Gruyter.

Frey, W. 2006b. How to get an object-es into the German prefield. In P. Brandt and E. Fuss, eds., Form, Structure, and Grammar - A Festschrift Presented to Günther Grewendorf on Occasion of His 60th Birthday, 159185. Berlin: Akademie Verlag.

Haeberli, E. and S. Pintzuk. 2017. V3 in true V2 contexts in Old English. Presented at the workshop V3 and Resumptive Adverbials. Universiteit Gent, 5 October 2017.

Haeberli, E., S. Pintzuk, and A. Taylor. 2017. Object pronoun fronting and the nature of V2 in early English. Ms. University of Geneva, University of York.

Light, C. 2012. The Syntax and Pragmatics of Fronting in Germanic. Ph.D. thesis, University of Pennsylvania.

Taylor, A. and S. Pintzuk. 2015. Verb order, object position and information status in Old English. In T. Biberauer and G. Walkden, eds., Syntax over Time: Lexical, Morphological and Information-Structural Interactions. Oxford: OUP.

Taylor, A. and S. Pintzuk. 2017. Split coordination in Early English. In 
B. Los and P. de Haan, eds., Word order change in acquisition and language contact: Essays in honour of Ans van Kemenade, 155-183. Amsterdam: John Benjamins.

Walkden, G. 2017. Language contact and V3 in Germanic varieties new and old. JCGL 20:49-81. 



\section{Appendix}

\section{Partial batch file for Old English data for Haeberli et al. 2017}

Within a UNIX platform, batch files are run by typing 'source [filenamel'. Blank lines and lines that start with the hash character (\#) are ignored; in this way comments can be added to describe the procedures and searches. In the file below, the executable lines are shown in red.

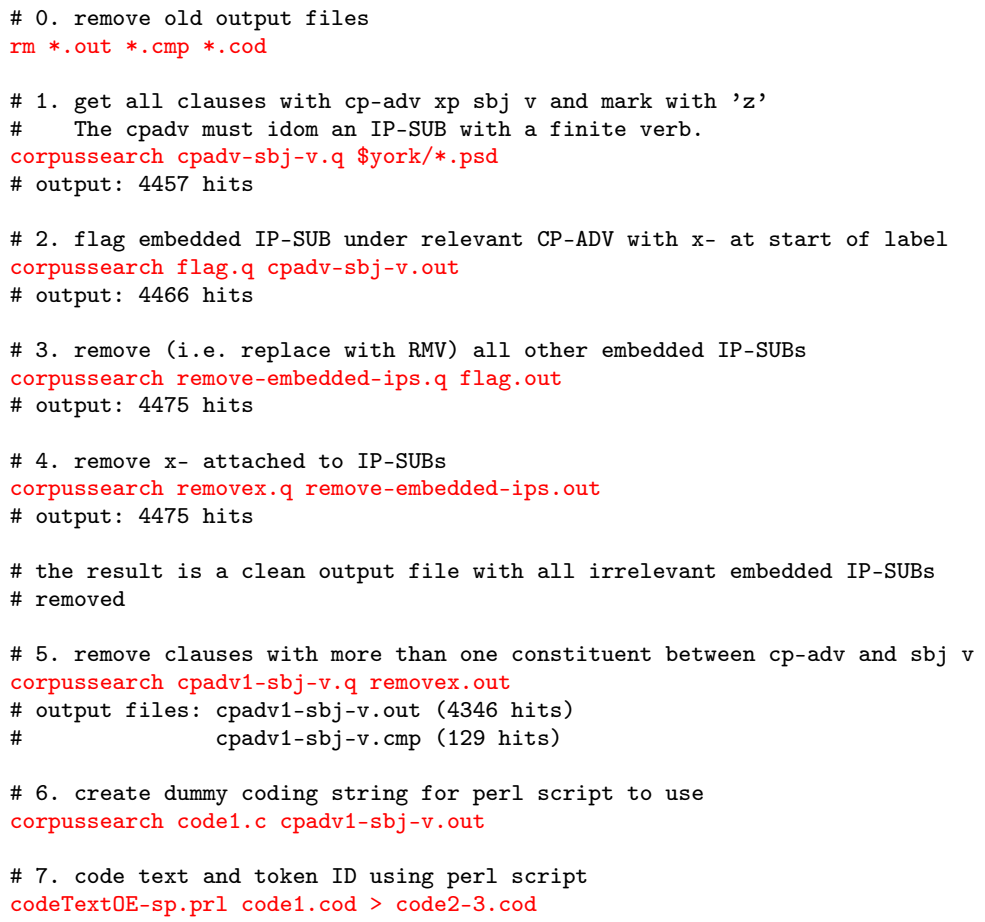


30 / AdDing Linguistic INFORMATion to PARSED CORPORA

\# 8. code $\mathrm{P}$ of $\mathrm{CP}-\mathrm{ADV}$, main/conjunct, order of verb and subject corpussearch code4-6. c code2-3. cod 


\section{Appendix B}

\section{Examples of NP types from Crisma and Pintzuk 2016}

(II.1) a. existential interpretation (CODE: $<$ NPTYPE:BSG-EXS $>$ )

Eue heold iparais

long tale wið be

Eve held in-paradise (a) long conversation with the

neddre

serpent

(CMANCRIW-1,II.54.520)

b. existential interpretation (CODE: <NPTYPE:AN-EXS >)

As ha beos bone hefde ibeden com a kempe When she this plea had made came a champion of helle on englene heowe from hell in angel's guise

'When she had made this plea, a champion came from hell in the guise of an angel'

(CMJULIA,107.187) 
(II.2) a. generic interpretation (CODE: <NPTYPE:BSG-GNR>) $\mathrm{pu}$ seist bt muche confort haueð wif of hire you say that much comfort has (a) wife from her were

husband 'you say that a wife has much comfort from her husband ...'

(CMHALI,147.282)

b. generic interpretation (CODE: <NPTYPE:AN-GNR $>$ ) Certes a shadwe hath the liknesse of the thyng of Certainly a shadow has the likeness of the thing of which it is shadwe which it is (the) shadow (CMCTPARS,292.C2.187)

(II.3) ambiguous between existential and generic

(CODE: <NPTYPE:AN-AMB $>$ )

And therfore seith a philosophre in this wise

And therefore says a philosopher in this manner

'And therefore a (particular) philosopher says / philosophers say in this manner ...'

(CMCTMELI,224.C1.277)

(II.4) existential specific nominal

(CODE: <NPTYPE:AN-EXS-SPC $>$ )

A yong man called Melibeus myghty and riche bigat A young man called Melibee mighty and rich begat upon his wyf that called was Prudence a doghter which upon his wife who called was Prudence a daughter who that called was Sophie that called was Sophie

'A young man called Melibee, mighty and rich, begat upon his wife, who was called Prudence, a daughter who was called Sophie.'

(CMCTMELI,217.C1b.5) 
Appendix B: Examples of NP types from Crisma And Pintzuk 2016 / 33

(II.5) existential nominal with narrow scope (CODE: <NPTYPE:AN-EXS-SCOPE-nrw >)

Ich chulle lete makie be of golt an ymage as cwen I shall let make thee of gold an image as queen icrunet

crowned

'I will have a golden image made of you as a crowned queen' (CMKATHE,36.269)

(II.6) existential nominal with wide scope

(CODE: <NPTYPE:AN-SCOPE-wd >)

\& seide to hire pus. haue cwen acrune isent te and said to her thus. have queen a-crown sent to-you of heouene

from heaven

'and (he) said the following to her: Queen, have a crown, sent to you from heaven'

(CMKATHE,38.308)

(II.7) existential nominal with ambiguous scope

(CODE: <NPTYPE:AN-SCOPE-amb>)

thanne seketh he an ydel solas of worldly then seeks he a useless consolation from worldly thynges

things

'then he seeks a useless consolation from worldly things' (CMCTPARS,313.C1.1073) 
34 / AdDing Linguistic INFORMATION TO PARSED CORPORA

(II.8) nominals that are ambiguous, either generic or narrow scope existential

a. (CODE $<$ NPTYPE:BSG-NPE $>$ )

tis put he hat bt beo ilided bt beast

this pit he commanded that be covered that beast

prin ne falle

therein NEG fall

'he commanded that this pit be covered lest (a) beast fall therein'

(CMANCRIW-1,II.48.446)

b. (CODE <NPTYPE:AN-NPE $>$ )

whan a gret lord hap no child he may chese a pore when a great lord has no child he may choose a poor mannes sone zif he wole and make of hym his eir bi man's son if he will and make of him his heir by adopcioun

adoption

'when a great lord has no child, he may choose a poor man's son if he wants and make him his heir by adoption'

(CMVICES4,100.63) 